\title{
Pain and health-related quality of life in people with chronic leg ulcers
}

\author{
W. M. Hopman, MA (1, 2); M. Buchanan, PHCNP, MSc (3); E. G. VanDenKerkhof, RN, DrPH (4, 5); \\ M. B. Harrison, RN, PhD (4)
}

This article has been peer reviewed.

\begin{abstract}
Introduction: Venous leg ulceration is associated with pain and poor health-related quality of life (HRQL). The purpose of this study was to identify demographic and clinical characteristics associated with pain and decreased HRQL in patients with active venous ulcers.
\end{abstract}

Methods: Baseline data were combined from two trials that took place between 2001 and 2007 ( $\mathrm{n}=564$ ). Pain was measured using the Numeric Pain Scale (NPS), and HRQL was measured using the Medical Outcomes Survey 12-item Short Form (SF-12), which generates a Physical (PCS) and Mental Component Summary (MCS). Analyses included logistic and linear regression (for pain and HRQL, respectively).

Results: Mean age was 66.5 years; $47 \%$ were male. Median NPS score was 2.2 (out of 10) and mean PCS and MCS scores were 38.0 and 50.5, respectively (scores are standardized to a mean of 50 representing average HRQL). Younger age, living with others, and arthritis were associated with pain. Poorer PCS was associated with being female, venous/mixed ulcer etiology, larger ulcers, longer ulcer duration, cardiovascular disease, arthritis and higher pain intensity. Poorer MCS was associated with younger age, longer ulcer duration, comorbidity and higher pain intensity.

Conclusion: Research is needed to test strategies to reduce pain and possibly improve HRQL in high risk groups.

Keywords: chronic, leg ulcers, SF-12, pain, HRQL, Medical Outcomes Survey 12-item Short Form, health-related quality of life

\section{Introduction}

A venous ulcer is a recurrent chronic wound on the lower leg. Venous ulceration mostly occurs among older adults, but onset can be as early as in the patient's twenties. ${ }^{1,2}$ The estimated prevalence of active venous ulcers is 0.8 to 1 per 1000 population. ${ }^{3}$ Improvements in practice and the organization of care have vastly improved rates of healing. ${ }^{4,5}$ However, even after 12 months of care, $20 \%$ will remain unhealed $^{6}$ and up to $34 \%$ will have recurred. ${ }^{7,8}$

The burden of illness for this population is considerable. Venous ulcers negatively affect mobility, employment, social roles, physical activity and quality of life. ${ }^{9-12}$ Pain is one of the most commonly reported side effects; ${ }^{13}$ a recent integrative review found that pain was the factor most frequently identified as affecting health-related quality of life (HRQL). ${ }^{14}$
Ulcer healing, along with HRQL, are of central concern to sufferers and wound care practitioners as these outcomes reflect the impact of chronicity, recurrence and symptom burden.

In considering chronicity and well-being, the Wilson and Cleary ${ }^{15}$ conceptualization proposes that HRQL is made up of four health outcomes aligned in a causal pathway and influenced by individual and environmental factors. The health outcomes are biological factors, which affect symptom status, which together affect functional status. The final one is general health perception, which is affected by the three outcomes that precede it in the causal path, and by individual and environmental factors.

Biological factors reflect cell, organ or system functioning and are frequently defined as indicators of disease severity. Within the context of venous leg ulcers, biological factors can include ulcer size, duration and etiology, as well as any comorbid conditions that the patient may have. The evidence is mixed regarding the association between ulcer size or duration and HRQL. ${ }^{13,16-18}$ Comorbidity in venous disease has not been extensively studied, although diabetes, arterial insufficiency and autoimmune diseases are generally thought to delay healing. One study reported that osteoarthritis was associated with ulcer pain. ${ }^{19}$

Symptom status is the person's perception of an abnormal physical, emotional or cognitive state. Ulceration is associated

Author references:

1. Clinical Research Centre, Kingston General Hospital, Kingston, Ontario, Canada

2. Department of Community Health \& Epidemiology, Queen's University, Kingston, Ontario, Canada

3. Napanee \& Area Community Health Centre, Napanee, Ontario, Canada

4. School of Nursing, Queen's University, Kingston, Ontario, Canada

5. Department of Anesthesiology \& Perioperative Medicine, Queen's University, Kingston, Ontario, Canada

Correspondence: Wilma M. Hopman, Clinical Research Centre, Kingston General Hospital, 76 Stuart Street, Kingston, ON K7L 2V7; Tel.: 613-549-6666 ext. 4941; Fax: 613-548-2428;

Email: hopmanw@kgh.kari.net 
with numerous symptoms including pain, wound drainage, itching, lower limb swelling and odour. ${ }^{20}$ of all these symptoms, pain has been the most researched, possibly because there are a number of validated methods for assessing pain. ${ }^{14}$ The impact of pain may be immense, causing even young, otherwise able-bodied individuals to seek leaves of absence, sick days, and even early retirement. ${ }^{21,22}$

In 1995, Wilson and Cleary ${ }^{15}$ defined functional status as the ability to perform normal tasks in a minimum of four domains, including physical, social, role and psychological. Venous disease symptoms negatively affect activities of daily living $9,11,20$ and physical function. ${ }^{10}$ Mobility may be impaired by swelling, ${ }^{21}$ and symptom burden may also negatively affect mental health. ${ }^{21,23}$ General health perception, a subjective overall rating of health, represents an integration or synthesis of biological factors, symptom status and functional status. ${ }^{15}$ For those with venous ulceration, reductions in the domain of general health perception (measured using the Medical Outcomes Short Form-36 Questionnaire) ranged from 3.3 to 13.3 , on a scale 0 to 100 , when compared with population normative scores ${ }^{24-26}$

Individual factors may also influence symptom status, functional status, health perceptions and quality of life. Price and Harding $^{24}$ did not find a difference between men and women in HRQL, but Lindholm ${ }^{27}$ and Franks et al. ${ }^{28}$ found that men experienced a greater impact in more domains of HRQL. Another study found that living with a spouse was associated with improved HRQL. ${ }^{29}$

The purpose of our study was to explore the relationship between clinical variables, pain and HRQL in patients with active venous ulcers. The Wilson and Cleary $^{15}$ model provided the basis for identifying variables of interest in our two primary research questions: (1) do age, gender, living conditions, comorbidity and leg ulcer size and duration affect pain intensity, and (2) do these same variables and pain intensity affect physical and mental HRQL?

\section{Methods}

Our sample consisted of individuals with leg ulcers who participated in two randomized controlled trials (RCTs) carried out between 2001 and 2007.,30 Ulcer healing was the primary outcome measure in both trials; HRQL and pain were secondary outcomes. The cross-sectional baseline assessment data from both trials formed the dataset for the current study. The original trials were reviewed for ethical compliance by the Queen's University and Affiliated Teaching Hospitals Research Ethics Board (the Canadian Bandaging Trial $^{30}$ ) and the Ottawa Health Research Institute Ethics Board (Nurse Clinic Versus Home Delivery $\mathrm{RCT}^{5}$ ); the current combined analysis was approved by the Queen's University and Affiliated Teaching Hospitals Research Ethics Board.

All trial participants received comprehensive, evidence-based assessments by nurses in homecare settings in several Canadian communities as well as in remote/rural areas. Participants in both studies had to be aged 18 years or older, give consent to participate, not have diabetes and have a venous or mixedvenous arterial ulcer. Further eligibility criteria included having an opening in the skin below the knee at least $0.7 \mathrm{~cm}$ in any dimension for at least one week and an ankle brachial pressure index of 0.8 or more. The ulcer was either a first occurrence or a recurrence.

HRQL was measured using the Medical Outcomes Survey 12-item Short Form (SF12). ${ }^{31}$ The SF-12 produces two scores, the Physical Component Summary (PCS) and the Mental Component Summary (MCS). The PCS is primarily based on the original Medical Outcomes Survey 36-item Short Form (SF-36) domains of physical functioning, role limitations due to physical health problems, bodily pain and general health perception, while the MCS is primarily based on the domains of vitality, social functioning, role limitation due to emotional problems and mental health. ${ }^{32}$ While the original domains are scored on a scale of 0 to 100 , the PCS and MCS are standardized to a mean of 50 , with scores above and below 50 representing better than and poorer than average summaries, respectively. ${ }^{31,32}$ A 2 to 3 point difference is considered clinically meaningful. ${ }^{31}$ The instrument has demonstrated good discriminatory function in numerous health conditions $^{33}$ and in two venous leg ulcer samples based on age, ulcer duration and mobility $^{17}$ and healed status at 12 months. ${ }^{16}$ Numerous leg ulcer studies have used this instrument to measure HRQL or quality of life. ${ }^{4,16,17,19,24-26,30,34,35}$

Pain was measured using two scales, the Numeric Pain Scale (NPS) and the Present Pain Intensity (PPI). The NPS ranges from zero ("no pain") and 10 (" most pain"). The median NPS score ( $\leq 2.2 / 10$ vs. $>2.2 / 10$ ) differentiated a lower pain group from a higher pain group. The PPI consists of six number-word combinations ranging from zero ("no pain") to five ("excruciating pain"). The PPI is part of the short form McGill Pain Questionnaire, ${ }^{36}$ and both the NPS and PPI have been used in diverse clinical populations including those with venous ulcers. ${ }^{16,19,37-39}$

Biological variables included ulcer size, duration and etiology, as well as comorbid conditions. The ulcer area was measured using computer planimetry of ulcer tracings and categorized as either equal or less than $5 \mathrm{~cm}^{2}$ or greater than $5 \mathrm{~cm}^{2}$. The duration of the ulcer was based on patient report and categorized as either equal or less than 6 months or greater than 6 months. Ulcer etiology and comorbid conditions were collected using the Leg Ulcer Assessment Tool. ${ }^{40}$ Patients identified relevant comorbid conditions from a list associated with different ulcer etiologies, such as heart disease, hypertension, renal disease, lower limb arterial disease and inflammatory bowel disease. Individual characteristics were defined as age (categorized as less than versus equal or more than 65 years), gender and social support (living alone or with others).

Using chi-square tests, we assessed the association between categorical variables and the two-level NPS pain measure, while Student's $t$-tests were used to assess the association between these variables and the two continuous HRQL measures. Multivariable logistic (pain) and linear (HRQL) regression was then used to identify the subset of significant factors 
associated with the three outcomes. Gender was forced into the regression models in light of preliminary evidence that HRQL scores differed between men and women with leg ulcers. All regression procedures used simultaneous entry. Variables were eliminated one at a time in successive regressions if $p$ was over .10 and retained if $p$ less than or equal to .10 so as not to miss clinically important trends. Odds ratios (ORs) and 95\% confidence intervals (CIs) are reported for the final multivariable models. Analyses were conducted using SPSS version 19.0 for windows (IBM, Chicago, IL, US).

\section{Results}

The sociodemographic and clinical profile of the 564 study participants is fairly typical of the population with leg ulcers (Table 1). Age ranged from 23 to 95 years, with a mean of 66.5 years and a standard deviation (SD) of 15.9; 340 (60.3\%) were over 65 years. There were more men in the younger group ( $<65$ years; $127 / 224$, $57 \%)$ and more women in the older group ( $\geq 65$ years; 201/340, 59\%) but the overall gender distribution was similar. Ulcers were predominantly due to venous disease $(488 / 564,86.5 \%)$ involving one leg. The median ulcer size was $3.4 \mathrm{~cm}^{2}$ and the median duration was 2.6 months. Approximately $60 \%$ had at least one comorbid condition, with arthritis being the most common $(211 / 564,37.4 \%)$. Onefifth of respondents $(114 / 564 ; 20.2 \%)$ reported no pain and $17.6 \%$ (99/564) reported pain that was "distressing" or worse (Table 2). The mean PCS was 38.0, well below the Canadian normative population mean of 50.5 , but the mean MCS was 50.5 , similar to the population normative score of $51.7 .^{41}$

Living with others $(p=.014)$, presence of comorbidities $(p=.031)$ and arthritis ( $p=.009$ ) were associated with pain of more than $2.2 / 10$ in bivariable analysis (Table 3 ). The final logistic regression model explained only $4 \%$ of the variance in pain intensity. In the multivariable model, living with others $(\mathrm{OR}=1.5$, $95 \%$ CI: $1.1-2.1, p=.023)$ and arthritis $(\mathrm{OR}=1.6,95 \% \mathrm{CI}: 1.1-2.2, p=.016)$ were independently associated with pain. Being older $(\mathrm{OR}=0.7,95 \% \mathrm{CI}$ : 0.5-1.0,
TABLE 1

Characteristics of study sample with chronic leg ulcers $(n=564)$

\begin{tabular}{lc} 
Characteristic & \\
\hline Male, $\mathrm{n}(\%)$ & $266(47.2)$ \\
Age, years & \\
$\quad$ Mean (SD) & $66.5(15.9)$ \\
Median & 69.0 \\
Range & $23-95$ \\
$\quad \geq 65$ years, $\mathrm{n}(\%)$ & $340(60.3)$ \\
Living alone, $\mathrm{n}(\%)$ & $203(36.0)$ \\
Current smoker, $\mathrm{n}(\%)$ & $75(13.3)$ \\
Presence of comorbidity ${ }^{\mathrm{a}}, \mathrm{n}(\%)$ & $346(61.3)$ \\
Arthritis & $211(37.4)$ \\
Cardiovascular disease ${ }^{\mathrm{b}}$ & $134(23.8)$ \\
Hypertension & $183(32.4)$ \\
Renal disease & $28(5.0)$ \\
Probable etiology, $\mathrm{n}(\%)$ & \\
Venous & $488(86.5)$ \\
Venous-mixed & $76(13.5)$ \\
Bilateral ulcers, $\mathrm{n}(\%)$ & $21(3.7)$ \\
Ulcer size & \\
Mean & $292(51.8)$ \\
Median & \\
Range & \\
Ulcer duration, months & \\
Mean & \\
Median & \\
Range & \\
$>$ & \\
\hline
\end{tabular}

Abbreviation: SD, standard deviation.

a Vasculitis, inflammatory bowel disease, arthritis, cardiovascular disease, hypertension, diabetes, renal disease.

b Cerebral vascular accident, transient ischemic attack, lower extremity arterial disease, myocardial infarction, angina, congestive heart failure.

$p=.052$ ) was also associated with pain but fell just short of statistical significance. Being male was associated with less pain but this was nonsignificant ( $p=.29$ ).

Bivariable tests for the PCS (Table 4) show that poorer physically related HRQL was significantly associated with several factors: older age $(p=.037)$, venous-mixed etiology $(p<.001)$, presence of comorbidities $(p<.001)$, cardiovascular disease $(p=.002)$, arthritis $(p<.001)$, hypertension $(p=.027)$ and an NPS score higher than $2.2(p<.001)$.
TABLE 2

Pain intensity and health-related quality of life characteristics for study sample with chronic leg ulcers $(n=564)$

\begin{tabular}{|c|c|}
\hline Outcome & \\
\hline \multicolumn{2}{|l|}{$N^{N} S^{a}$} \\
\hline Mean & 2.9 \\
\hline Median & 2.2 \\
\hline Range & $0-10$ \\
\hline \multicolumn{2}{|c|}{ NPS categorized at the median, $\mathrm{n}(\%)$} \\
\hline$\leq 2.2$ & $287(50.9)$ \\
\hline$>2.2$ & $277(49.1)$ \\
\hline \multicolumn{2}{|l|}{$\mathrm{PPI}^{\mathrm{b}}, \mathrm{n}(\%)$} \\
\hline No pain & $114(20.2)$ \\
\hline Mild & $157(27.8)$ \\
\hline Discomforting pain & $194(34.4)$ \\
\hline Distressing & $53(9.4)$ \\
\hline Horrible & $25(4.4)$ \\
\hline Excruciating & $21(3.7)$ \\
\hline \multicolumn{2}{|l|}{$\mathrm{PCS}^{\mathrm{c}}$} \\
\hline Mean & 38.0 \\
\hline Median & 37.9 \\
\hline Range & $11.6-65.0$ \\
\hline \multicolumn{2}{|l|}{$\mathrm{MCS}^{\mathrm{d}}$} \\
\hline Mean & 50.5 \\
\hline Median & 52.3 \\
\hline Range & $20.5-69.3$ \\
\hline
\end{tabular}

Abbreviations: HRQL, health-related quality of life; MCS, Mental Component Summary; NPS, Numeric Pain Scale; PCS, Physical Component Summary; PPI, Present Pain Index.

a The NPS ranges from zero ("no pain") to 10 ("most pain"). The median NPS score ( $\leq 2.2 / 10$ vs. $>2.2 / 10$ ) differentiated a lower pain group from a higher pain group.

b The PPI consists of six number-word combinations ranging from 0 ("no pain") to 5 ("excruciating pain").

c Physical Component Summary of the Medical Outcomes Survey 12-item Short Form (SF-12), ${ }^{31}$ centred to 50 with scores over 50 and under 50 representing better than and poorer than average scores respectively, range 8-73.

d Mental Component Summary of the Medical Outcomes Survey 12-item Short Form (SF-12), ${ }^{31}$ centred to 50 with scores over 50 and under 50 representing better than and poorer than average scores respectively, range 9-74.

The coefficients and the associated 95\% CIs for the final regression model are also shown in Table 4. The model explained $10.5 \%$ of the variability in outcome. Arthritis and an NPS score higher than 2.2 were both independently associated with a poorer PCS ( $p<.001$ for both), as were mixed etiology ( $p=.002$ ) and longer ulcer duration ( $p=$.006). Cardiovascular 
TABLE 3

Bivariable associations for pain intensity and final logistic regression model

\begin{tabular}{|c|c|c|c|c|c|}
\hline \multirow[t]{2}{*}{ Variable $^{\mathrm{a}}$} & \multicolumn{3}{|c|}{ Bivariable associations ( $\chi^{2}$ tests) } & \multicolumn{2}{|c|}{ Final regression model ${ }^{\mathbf{b}}$} \\
\hline & $\begin{array}{c}0-2.2^{c} \\
\text { n (\%) }\end{array}$ & $\begin{array}{c}2.3-10^{c} \\
n(\%)\end{array}$ & $p$ value & OR $(95 \% \mathrm{Cl})$ & $p$ value \\
\hline \multicolumn{6}{|l|}{ Sex } \\
\hline Female (0) & $145(48.7)$ & $153(51.3)$ & .30 & 1.0 & $.29^{\mathrm{d}}$ \\
\hline Male (1) & $142(53.0)$ & $125(47.0)$ & & $0.83(0.6,1.2)$ & \\
\hline \multicolumn{6}{|l|}{ Age } \\
\hline$<65$ years $(0)$ & $104(46.4)$ & $120(53.6)$ & .10 & 1.0 & $.052^{\mathrm{d}}$ \\
\hline$\geq 65$ years $(1)$ & $182(53.5)$ & $158(46.5)$ & & $0.71(0.5,1.0)$ & \\
\hline \multicolumn{6}{|l|}{ Social support } \\
\hline Lives alone (0) & $117(57.6)$ & $86(42.4)$ & .014 & 1.0 & .023 \\
\hline Lives with others (1) & $169(46.8)$ & $192(53.2)$ & & $1.5(1.1,2.1)$ & \\
\hline \multicolumn{6}{|l|}{ Smoking status } \\
\hline Current smoker & $34(45.3)$ & $41(54.7)$ & .32 & & \\
\hline Non-smoker & $252(51.5)$ & $237(48.5)$ & & & \\
\hline \multicolumn{6}{|l|}{ Ulcer size } \\
\hline$\leq 5 \mathrm{~cm}^{2}$ & $163(47.9)$ & $177(52.1)$ & .09 & & \\
\hline$>5 \mathrm{~cm}^{2}$ & $123(55.2)$ & $100(44.8)$ & & & \\
\hline \multicolumn{6}{|l|}{ Ulcer duration } \\
\hline$\leq 6$ months & $200(48.7)$ & $211(51.3)$ & .11 & & \\
\hline$>6$ months & $86(56.2)$ & $67(43.8)$ & & & \\
\hline \multicolumn{6}{|l|}{ Etiology } \\
\hline Venous & $251(51.4)$ & 237 (48.6) & .38 & & \\
\hline Venous-mixed & $35(46.1)$ & $41(53.9)$ & & & \\
\hline \multicolumn{6}{|l|}{ Presence of comorbidity } \\
\hline Yes & $163(47.1)$ & $183(52.9)$ & .031 & & \\
\hline No & $123(56.4)$ & $95(43.6)$ & & & \\
\hline \multicolumn{6}{|c|}{ Cardiovascular comorbidities } \\
\hline Yes & $61(45.5)$ & $73(54.5)$ & .20 & & \\
\hline No & $225(52.3)$ & $205(47.7)$ & & & \\
\hline \multicolumn{6}{|l|}{ Arthritis } \\
\hline Yes (1) & $92(32.2)$ & 119 (42.8) & .009 & $1.6(1.1,2.2)$ & .016 \\
\hline No $(0)$ & $194(67.8)$ & $159(57.2)$ & & 1.0 & \\
\hline \multicolumn{6}{|l|}{ Hypertension } \\
\hline Yes & $97(53)$ & $86(47)$ & .45 & & \\
\hline No & $189(49.6)$ & $192(50.4)$ & & & \\
\hline
\end{tabular}

Abbreviations: $\mathrm{Cl}$, confidence interval; NPS, Numeric Pain Scale; OR, odds ratio.

a Values in parentheses represent the variable coding for the linear regression model. Sex was forced into the model.

b $r^{2}$ Cox \& Snell for multivariable model $=0.04$.

"The NPS ranges from zero ("no pain") to ten ("most pain"). The median NPS score ( $\leq 2.2 / 10 \mathrm{vs.}>2.2 / 10)$ differentiated a lower pain group from a higher pain group.

${ }^{d}$ Not statistically significant but of interest empirically (sex) or clinically important (age) and therefore retained in the model.

comorbidity ( $p=.058)$ and a larger ulcer size $(p=.09)$ were also associated with a lower PCS. While they fell short of statistical significance, they were deemed clinically important and therefore retained in the model.
Further, the results of bivariable and multivariable tests for the MCS (Table 5) reveal that those aged over 65 years report a better MCS compared with those aged under 65 years ( $p=.006$ ), while those with higher pain intensity reported a poorer MCS $(p<.001)$. Sex was not significant $(p=.6)$. Only one additional variable, presence of comorbidity, showed a trend towards a poorer MCS ( $p=.058$ ). The coefficients and the associated 95\% CIs for the final regression model are also shown in Table 5 . The model explained $7.8 \%$ of the variability in outcome. Older age was associated with a better MCS ( $p=.005)$, while presence of comorbidity and higher pain intensity were both associated with a poorer MCS ( $p=.014$ and $p<.001$ respectively). Longer ulcer duration ( $p=.053$ ) was also associated with a poorer MCS; while it fell short of statistical significance, it was considered clinically important and retained in the model.

\section{Discussion}

To our knowledge, this is one of the largest studies to explore the relationships between routinely measured clinical variables and HRQL in a clinically validated venous ulcer population. We found substantial support for the associations between individual, environmental and clinical variables, pain and HRQL in this population.

Women tended to report somewhat higher pain and poorer PCS and MCS scores, but the results were not statistically significant in any of the three models. Younger participants tended to report more pain and a poorer MCS, but age was just short of being significant in the final regression model of the PCS. The PCS is known to decline with age, ${ }^{40}$ and we therefore anticipated a relatively poor PCS in the older adult group. The large sample size ensured a good representation of younger and older adults, and the lack of effect is therefore not due to homogeneity of the independent variable. One explanation is that the younger group had poorer PCS scores than expected and therefore nullified the effect of age. This would lend support to earlier findings that those younger than 65 years had a greater deviation from HRQL norms than those who are older, ${ }^{28}$ which is supported by the fact that the mean PCS for both groups was well below the Canadian normative value. ${ }^{40}$ It is also possible that there was colinearity with some of the other variables such as arthritis, which was far more common in the older age group. However, 
TABLE 4

Bivariable associations for the SF-12 Physical Component Summary and final multivariable linear regression model

\begin{tabular}{|c|c|c|c|c|}
\hline \multirow[t]{2}{*}{ Variable $^{\mathrm{a}}$} & \multicolumn{2}{|c|}{ Bivariable associations $^{b}$} & \multicolumn{2}{|c|}{ Final regression model } \\
\hline & Mean (SD) & $p$ value & $\begin{array}{c}\text { Coefficient } \\
(95 \% \mathrm{Cl})\end{array}$ & $p$ value \\
\hline Constant for model & & & $42.8(41.0,44.6)$ & \\
\hline \multicolumn{5}{|l|}{ Sex } \\
\hline Female (0) & $37.3(9.7)$ & .077 & $1.1(-0.5,2.8)$ & .18 \\
\hline Male (1) & 38.9 (10.7) & & & \\
\hline \multicolumn{5}{|l|}{ Age } \\
\hline$<65$ years & 39.1 (9.9) & .037 & & \\
\hline$\geq 65$ years & $37.3(10.4)$ & & & \\
\hline \multicolumn{5}{|l|}{ Smoking status } \\
\hline Current smoker & $39.3(10.3)$ & .25 & & \\
\hline Non-smoker & $37.5(10.2)$ & & & \\
\hline \multicolumn{5}{|l|}{ Social support } \\
\hline Lives alone & $37.5(10.2)$ & .34 & & \\
\hline Lives with others & $38.4(10.2)$ & & & \\
\hline \multicolumn{5}{|l|}{ Ulcer size } \\
\hline$\leq 5 \mathrm{~cm}^{2}(0)$ & $38.6(10.8)$ & .10 & $-1.4(-3.1,0.2)$ & $.09^{c}$ \\
\hline$>5 \mathrm{~cm}^{2}(1)$ & $37.2(9.1)$ & & & \\
\hline \multicolumn{5}{|l|}{ Ulcer duration } \\
\hline$\leq 6$ months $(0)$ & $38.5(11.1)$ & .09 & $-2.6(-4.5,-0.7)$ & .006 \\
\hline$>6$ months (1) & $36.9(9.3)$ & & & \\
\hline \multicolumn{5}{|l|}{ Leg ulcer etiology } \\
\hline Venous $(0)$ & $38.7(10.2)$ & $<.001$ & $-3.9(-6.4,-1.5)$ & .002 \\
\hline Venous-mixed (1) & $33.6(9.2)$ & & & \\
\hline \multicolumn{5}{|c|}{ Presence of comorbidity } \\
\hline Yes & $36.5(10.5)$ & $<.001$ & & \\
\hline No & $40.5(9.2)$ & & & \\
\hline \multicolumn{5}{|l|}{ Cardiovascular disease } \\
\hline Yes (1) & $35.4(11.0)$ & .002 & $-2.0(-3.9,0.1)$ & $.058^{c}$ \\
\hline No $(0)$ & $38.9(9.7)$ & & & \\
\hline \multicolumn{5}{|l|}{ Arthritis } \\
\hline Yes (1) & $35.3(10.5)$ & $<.001$ & $-3.4(-5.1,-1.6)$ & $<.001$ \\
\hline No (0) & $39.7(9.7)$ & & & \\
\hline \multicolumn{5}{|l|}{ Hypertension } \\
\hline Yes & $36.7(9.8)$ & .027 & & \\
\hline No & $38.7(10.3)$ & & & \\
\hline \multicolumn{5}{|l|}{ Pain $^{d}$} \\
\hline$\leq 2.2(0)$ & $39.9(9.7)$ & $<.001$ & $-3.5(-5.1,-1.9)$ & $<.001$ \\
\hline$>2.2(1)$ & $36.1(10.2)$ & & & \\
\hline
\end{tabular}

Abbreviations: $\mathrm{Cl}$, confidence interval; NPS, Numeric Pain Scale; $R^{2}$, coefficient of determination; SD, standard deviation; SF12, Medical Outcomes Survey 12-item Short Form.

${ }^{a}$ Values in parentheses represent the variable coding for the linear regression model. Sex was forced into the model. Adjusted $R^{2}$ for the model $=.11$

b Results of Student's $t$-tests.

c Not statistically significant but of interest empirically (sex) or clinically important (size, cardiovascular disease) and therefore retained in the model.

${ }^{d}$ Based on the median NPS score differentiating a lower pain group $(\leq 2.2 / 10)$ from a higher pain group $(>2.2 / 10)$. taking out individual variables and rerunning the models had little effect on the other regression coefficients, suggesting that colinearity was minimal.

Younger age was associated with higher pain scores, despite the probable increase in comorbid conditions associated with pain in the older group. There was no statistically significant difference in ulcer characteristics between younger and older adults, therefore a biological basis for a difference in pain intensity is improbable. It is possible that younger adults have higher expectations and are more likely to be active due to work and family than older adults, which may exacerbate pain. Unfortunately, we cannot test this hypothesis due to the lack of a measure of functional status in our study. Another possibility is that older and younger adults experience or report pain intensity differently; however, there is no evidence to support this and much of the literature suggests pain intensity increases with age. $^{42}$ Both the PCS and the MCS were very significantly and negatively associated with a higher pain level, as expected.

Neither size nor duration of ulcer were significantly associated with pain levels in bivariable or multivariable testing, although trends existed for higher levels of pain in smaller ulcers and in those of shorter duration. Studies of the relationship between size or duration of ulcers and pain intensity have been limited. Pieper et $\mathrm{al}^{43}$ found a moderate correlation between very large wounds and pain intensity (Pearson $r=0.44$ ). Walters et al. ${ }^{16}$ found an association between venous ulcers larger than $5.6 \mathrm{~cm}^{2}$ and a higher daytime pain score in their large crosssectional study. Our results do not support either of these studies, possibly due to methodological differences. Pieper et al. ${ }^{43}$ recruited a small number of younger adults with large venous ulcers who also had addiction issues. Moreover, of the four temporal measures of pain, only daytime pain intensity was associated with ulcer size. It may be that the relationship of pain intensity and ulcer characteristics is neither simple nor linear. Clinically, small ulcers associated with perforator vein incompetence or hypopig- 
TABLE 5

Bivariable associations (Student's $t$-tests) for the SF-12 Mental Component Summary and final multivariable linear regression model

\begin{tabular}{|c|c|c|c|c|}
\hline \multirow[t]{2}{*}{ Variable $^{\mathrm{a}}$} & \multicolumn{2}{|c|}{ Bivariable associations ${ }^{\mathbf{b}}$} & \multicolumn{2}{|c|}{ Final regression model } \\
\hline & Mean (SD) & $p$ value & Coefficient $(95 \% \mathrm{CI})$ & $p$ value \\
\hline Constant for model & & & $53.2(54.1,55.5)$ & \\
\hline \multicolumn{5}{|l|}{ Sex } \\
\hline Female (0) & $50.3(10.6)$ & .61 & $0.4(-1.3,2.1)$ & .63 \\
\hline Male (1) & $50.8(10.2)$ & & & \\
\hline \multicolumn{5}{|l|}{ Age } \\
\hline$<65$ years $(0)$ & $49.0(11.0)$ & .006 & $2.6(0.8,4.4)$ & .005 \\
\hline$\geq 65$ years $(1)$ & $51.5(9.8)$ & & & \\
\hline \multicolumn{5}{|l|}{ Smoking status } \\
\hline Current smoker & $48.8(11.1)$ & .12 & & \\
\hline Non-smoker & $50.8(10.3)$ & & & \\
\hline \multicolumn{5}{|l|}{ Social support } \\
\hline Lives alone & $50.0(10.6)$ & .46 & & \\
\hline Lives With others & $50.3(10.3)$ & & & \\
\hline \multicolumn{5}{|l|}{ Ulcer size } \\
\hline$\leq 5 \mathrm{~cm}^{2}$ & $50.5(10.4)$ & .83 & & \\
\hline$>5 \mathrm{~cm}^{2}$ & $50.7(10.4)$ & & & \\
\hline \multicolumn{5}{|l|}{ Ulcer duration } \\
\hline$\leq 6$ months $(0)$ & $50.9(10.1)$ & .16 & $-1.9(-3.9,0.0)$ & $.053^{\mathrm{c}}$ \\
\hline$>6$ months ( 1$)$ & $49.5(10.6)$ & & & \\
\hline \multicolumn{5}{|l|}{ Leg ulcer etiology } \\
\hline Venous & $50.6(10.5)$ & .59 & & \\
\hline Venous-mixed & $50.0(10.0)$ & & & \\
\hline \multicolumn{5}{|c|}{ Presence of comorbidity } \\
\hline Yes (1) & $50.0(10.8)$ & .058 & $-2.3(-4.2,-0.5)$ & .014 \\
\hline No $(0)$ & $51.4(9.7)$ & & & \\
\hline \multicolumn{5}{|l|}{ Cardiovascular disease } \\
\hline Yes & $50.1(10.6)$ & .78 & & \\
\hline No & $50.7(10.3)$ & & & \\
\hline \multicolumn{5}{|l|}{ Arthritis } \\
\hline Yes & $50.3(10.8)$ & .26 & & \\
\hline No & $50.7(10.1)$ & & & \\
\hline \multicolumn{5}{|l|}{ Hypertension } \\
\hline Yes & $51.0(10.2)$ & .56 & & \\
\hline No & $50.3(10.4)$ & & & \\
\hline \multicolumn{5}{|l|}{ Pain $^{d}$} \\
\hline$\leq 2.2(0)$ & $53.1(9.5)$ & $<.001$ & $-4.9(-5.6,-3.2)$ & $<.001$ \\
\hline
\end{tabular}

Abbreviations: $\mathrm{Cl}$, confidence interval; NPS, Numeric Pain Scale; $R^{2}$, coefficient of determination; SD, standard deviation; SF12, Medical Outcomes Survey 12-item Short Form.

${ }^{\text {a }}$ Values in parentheses represent the variable coding for the linear regression model. Sex was forced into the model. Adjusted $R^{2}$ for the model $=.08$

b Results of Student's $t$-tests.

c Not statistically significant but of interest empirically (sex) or clinically important (duration) and therefore retained in the model.

${ }^{d}$ Based on the median NPS score differentiating a lower pain group $(\leq 2.2 / 10)$ from a higher pain group $(>2.2 / 10)$. mented areas of atrophie blanche may be associated with severe pain, ${ }^{44}$ and older ulcers may be associated with less pain. $^{24,45}$ The relationship between ulcer characteristics, disease severity and pain merits further research.

The final regression models only accounted for a small proportion of the variance in pain intensity and HRQL. This may be due to several factors. One is that the causal associations in the Wilson and Cleary ${ }^{15}$ model pathway are weak, but it is more likely that the measures of biological characteristics and symptom status were incomplete and represent a subset of a much larger group. The best way to conceptualize biological characteristics is unclear. $^{46}$ Ulcer size and duration are clinically well-accepted proxies of ulcer severity but the list from which the patients identified their comorbidities, originally designed to aid in the process of differential diagnosis, may have poorly reflected the severity of comorbidity, a potentially important measure in this predominantly older population. In addition, we selected pain intensity, only one indicator of the range of symptoms associated with ulcers. Further, the NPS may not capture salient aspects of the pain experience, such as the affective experience of pain and pain-related interference. A third possibility is that a number of variables that contribute to HRQL, for example, functional status, were not measured within the scope of these two trials. Certainly, there is ample evidence that physical function is impaired during active ulceration. The inclusion of a robust measure of functional status may have increased the explanatory power of these models.

Although the explained variance of the models was limited, we found clinically important relationships between sociodemographic and biological characteristics, pain intensity and HRQL. A clinical scenario commonly found in many nurses' caseloads best illustrates this: Consider an individual who is 67 years old and has had a venous ulcer for 8 months. Osteoarthritis complicates their pain experience, and they rate their pain as 4 on a scale of 0 to 10 . Based on these characteristics and the coefficients from the regression model, 
we calculate a 14.7-point reduction in physical HRQL and a 7.6-point reduction in mental HRQL. This reduction in HRQL score is clinically important and illustrates the important linkages between routinely measured clinical characteristics and HRQL.

\section{Strengths and limitations}

Our study had several limitations. First, causation cannot be tested using a crosssectional design. Secondly, as a secondary analysis, the study variables were designed to answer different questions. For example, symptom status may have been more effectively measured using a validated disease-specific symptom-based tool in addition to pain intensity. Other important concepts such as functional status were not included.

Strengths of the study include the large sample size and use of validated tools to measure pain and HRQL. In addition, the primary RCTs upon which this analysis is based used consistent and validated approaches to evaluate ulcer size and duration. Finally, the large sample from both urban and rural settings is likely to be reasonably representative of clinical populations receiving treatment for venous ulcers.

Future research should define or test existing disease-specific measures of symptom status as a next step in the development of a clinically relevant model of HRQL. In addition, key concepts such as comorbidity and disease severity need further conceptualization. Finally, age is an important variable to explore in future studies with a robust measure of functional status. Impairment of physical function and other aspects of functional status in relation to age-normative expectations may play a key role in mediating the effect of age and pain on HRQL.

The assessment of HRQL is complex. It is likely that ulcer characteristics and pain intensity, two variables that clinicians frequently measure, account for a limited proportion of HRQL. Both variables are insufficient assessment parameters of HRQL in isolation. As a starting point, the impact of ulceration on daily life is an important topic to discuss with patients and should be incorporated into assessments and care planning. Understanding the impact of symptoms on function may be critically important in prioritizing goals and patient-centred evaluation of interventions.

\section{Acknowledgements}

The Nurse Clinic Versus Home Delivery of Evidence-based Community Leg Ulcer Care RCT was funded by a grant from the Medical Research Council (\#MOP42497), now the Canadian Institutes of Health Research. The Canadian Bandaging Trial was funded by a grant from the Canadian Institutes of Health Research (CIHR \#63175, CIHR funded trials ISRCTN37782978).

\section{References}

1. Callam MJ, Harper DR, Dale JJ, Ruckley CV. Chronic ulcer of the leg: clinical history. Br Med J. 1987;294:1389-91.

2. Graham ID, Harrison MB, Nelson EA, Lorimer K, Fisher A. Prevalence of lowerlimb ulceration: a systematic review of prevalence studies. Adv Skin Wound Care. 2003;16(6):305-16.

3. Callam MJ. Leg ulcer and chronic venous insufficiency in the community. In: Ruckley CV, Fowkes FG, Bradbury A, editors. Venous disease: epidemiology, management and delivery of care. London: Springer; 1999. 15-25

4. Harrison MB, Graham ID, Lorimer K, Friedberg E, Pierscianowski T, Brandys T. Leg-ulcer care in the community, before and after implementation of an evidence-based service. CMAJ. 2005;172(11):1447-52.

5. Harrison MB, Graham ID, Lorimer K, et al. Nurse clinic versus home delivery of evidence-based community leg ulcer care: a randomized health services trial. BMC Health Serv Res. 2008;8(1):243.

6. Nelson EA. Health related quality of life measurement. EWMA Journal. 2002;2(1):5-7.

7. Barwell JR, Davies CE, Deacon F, et al. Comparison of surgery and compression with compression alone in chronic venous ulceration (ESCHAR study): randomised controlled trial. Lancet. 2004;363(9424):1854-9.
8. Morrell CJ, Walters SJ, Dixon S, Collins KA, Brereton LML, Peters J. Cost effectiveness of community leg ulcer clinics: randomised controlled trial. BMJ. 1999;316(7143):1487-91.

9. Persoon A, Heinen MM, van der Vleuten CJ, de Rooij MJ, van de Kerkhof PC, van Achterburg T. Leg ulcers: a review of their impact on daily life. $\mathrm{J}$ Clin Nurs. 2004;13(3):341-54.

10. Herber OR, Schnepp W, Rieger MA. A systematic review on the impact of leg ulceration on patients' quality of life. Health Qual Life Outcomes. 2007;5:44-66.

11. Briggs M, Flemming K. Living with leg ulceration: a synthesis of qualitative research. J Adv Nurs. 2007;59(4):319-28.

12. Green J, Jester R. Health-related quality of life and chronic venous leg ulceration: part 2. Br J Community Nurs. 2010;15(3):S4-6, S8, S10, passim.

13. Hareendran A, Bradbury A, Budd J, et al. Measuring the impact of venous leg ulcers on quality of life. J Wound Care. 2005;14(2):53-7.

14. Gonzalez-Consuegra RV, Verdu J. Quality of life in people with venous leg ulcers: an integrative review. J Adv Nurs. 2011;67(5):926-44.

15. Wilson IB, Cleary PD. Linking clinical variables with health-related quality of life. A conceptual model of patient outcomes. JAMA. 1995;273(1):59-65.

16. Walters SJ, Morrell CJ, Dixon S. Measuring health-related quality of life in patients with venous leg ulcers. Qual Life Res. 1999;8:327-36.

17. Iglesias CP, Birks $\mathrm{Y}$, Nelson EA, Scanlon E, Cullum NA. Quality of life of people with venous leg ulcers: a comparison of the discriminative and responsive characteristics of two generic and a disease specific instrument. Qual Life Res. 2005;14:1705-18.

18. Franks PJ, Moffatt CJ. Do clinical and social factors predict quality of life in leg ulceration? Int J Low Extrem Wounds. 2006;5(4): 236-43.

19. Nemeth KA, Harrison MB, Graham ID, Burke S. Pain in pure and mixed aetiology venous leg ulcers: a three-phase point prevalence study. J Wound Care. 2003;12(9):336-40. 
20. Moffatt CJ, Harper P. Leg ulcers (access to clinical education). New York (NY): Churchill Livingstone; 1997.

21. Phillips T, Stanton B, Provan A, Lew R. A study of the impact of leg ulcers on quality of life: financial, social, and psychologic implications. J Am Acad Dermatol. 1994:31:49-53.

22. Krasner D. Painful venous ulcers: themes and stories about living with the pain and suffering. J Wound Ostomy Continence Nurs. 1998;25:158-68.

23. Franks PJ, Moffatt CJ. Quality of life issues in chronic wound management. $\mathrm{Br} \mathrm{J}$ Community Nurs. 1999;4(6):283-9.

24. Price P, Harding K. Measuring healthrelated quality of life in patients with chronic leg ulcers. Wounds. 1996;8(3):91-4.

25. Franks PJ, McCullagh L, Moffatt CJ. Assessing quality of life in patients with chronic leg ulceration using the Medical Outcomes Short Form-36 Questionnaire. Ostomy Wound Manage. 2003;49(2):26-37.

26. Jull A, Walker N, Hackett M, et al. Leg ulceration and perceived health: a population based case-control study. Age Ageing. 2004;33:236-41.

27. Lindholm C, Bjellerup M, Christensen OB, Zederfeldt B. Quality of life in chronic leg ulcer patients. An assessment according to the Nottingham Health Profile. Acta Derm Venereol. 1993;73(6):440-443.

28. Franks PJ, Moffatt CJ. Who suffers most from leg ulceration? J Wound Care. 1998;7(8):383-5.

29. Moffatt CJ, Franks PJ, Doherty DC, Smithdale R, Martin R. Sociodemographic factors in chronic leg ulceration. $\mathrm{Br} \mathrm{J}$ Dermatol. 2006;155:307-12.

30. Harrison MB, Vandenkerkhof EG, Hopman WM, Graham ID, Carley ME, Nelson EA. The Canadian Bandaging Trial: evidenceinformed leg ulcer care and the effectiveness of two compression technologies. BMC Nurs. 2011;10(1):20.

31. Ware JE, Kosinski M, Keller SD. SF-36 Physical and mental health summary scales: a user's manual and interpretation guide. Boston (MA): The Health Institute, New England Medical Center; 1994.
32. Ware JE, Sherbourne CD. The MOS 36-item short-form health survey (SF-36). I: conceptual framework and time selection. Med Care. 1992;30:473-83.

33. Ware JE. SF-36 Health Survey Update. In: Maruish ME, , editor. The use of psychological testing for planning and outcomes assessment 3rd ed. Mahwah (NJ): Lawrence Erlbaum Associates; 2004. 693-718.

34. Charles H. Does leg ulcer treatment improve patients' quality of life? J Wound Care. 2004;13(6):209-13.

35. Harrison MB, VanDenKerkhof E, Hopman WM, Graham ID, Lorimer K, Carley M. Evidence-informed leg ulcer care: a cohort study comparing outcomes of individuals choosing nurse-led clinic or home care. Ostomy Wound Manage. 2011;57(8):38-45.

36. Melzack R. The short-form McGill Pain Questionnaire. Pain. 1987;30(2):191-7.

37. Briggs M, Bennett MI, Closs SJ, Cocks K. Painful leg ulceration: a prospective, longitudinal cohort study. Wound Repair Regen. 2007;15:186-91.

38. Charles H. Venous leg ulcer pain and its characteristics. J Tissue Viability. 2002;12(4):154-8.

39. Noonan L, Burge SM. Venous leg ulcers: Is pain a problem? Phlebology. 1998;13:14-9.

40. Registered Nurses' Association of Ontario (RNAO). Learning package. Assessment and management of venous leg ulcers [Internet]. Nursing Best Practice Guidelines Program. Toronto (ON): Registered Nurses Association of Ontario; 2006 [cited 2012 May 2]. Available from: http://rnao.ca/sites/rnao-ca /files/Assessment_and_Management_of _Venous_Leg_Ulcers_-_Learning_Package.pdf

41. Hopman WM, Towheed T, Anastassiades $\mathrm{T}$, et al. Canadian normative data for the SF-36 health survey. Canadian Multicentre Osteoporosis Study Research Group. CMAJ. 2000;163(3):265-71.

42. Reitsma ML, Tranmer JE, Buchanan DM, Vandenkerkhof EG. The prevalence of chronic pain and pain-related interference in the Canadian population from 1994 to 2008 . Chronic Dis Inj Can. 2011;31(4):157-64.
43. Pieper B, Rossi R, Templin T. Pain associated with venous ulcers in injecting drug users. Ostomy Wound Manage. 1998;44(11):54-67.

44. Kunimoto BT. Assessment of venous leg ulcers: an in-depth discussion of a literature-guided approach. Ostomy Wound Manage. 2001;47(5):38-53.

45. Husband LL. Venous ulceration: the pattern of pain and the paradox. Clin Eff Nurs. 2001;5:35-40.

46. Sousa KH, Holzemer WL, Henry SB, Slaughter R. Dimensions of health-related quality of life in persons living with HIV disease. J Adv Nurs. 1999;29(1):178-87. 